\section{Epidemiological survey on the prevalence of Salmonella spp. in the Sardinian pig production chain, using real-time PCR screening method}

\author{
Carlo Pala, ${ }^{1}$ Tiziana Tedde, ${ }^{1}$ \\ Sara Salza, ${ }^{1}$ Maria Teresa Uda, ${ }^{1}$ \\ Stefano Lollai, ${ }^{2}$ Vittoria Carboni, ${ }^{2}$ \\ Antonio Fadda, ${ }^{1}$ Edoardo Marongiu, ${ }^{1}$ \\ Sebastiano Virgilio ${ }^{1}$ \\ ${ }^{1}$ Department of Food Hygiene, and \\ ${ }^{2}$ Department Animal Health, Institute \\ for Experimental Veterinary Medicine of \\ Sardinia, Sassari, Italy
}

\begin{abstract}
The aim of this study was to evaluate the prevalence of Salmonella spp. in the Sardinian pig production chain in order to establish the incidence of monophasic serovariant of Salmonella Typhimurium on isolates with molecular methods (real-time PCR and multiplex PCR). Samples were collected in three EC slaughterhouses, four small slaughterhouses annexed to farmhouses, one meat distribution center, four meat cutting laboratories and four sausage processing plants. A total of 166 samples were collected and analyzed: 46 environmental samples, 48 finishing pigs, 16 al., 2009; Ido et al., 2014). The Center for Disease Control and Prevention (CDC) reported that the prevalence of monophasic serovariant of Salmonella Typhimurium has increased considerably in many Countries in the world over the last 10 years. The diffusion of this Salmonella serotype was responsible for many human salmonellosis outbreaks, including the ones in Spain in 1998, in the United States in 2004 and 2007, and in Luxemburg in 2006 (Agasan et al., 2002; Mossong et al., 2007). The monophasic serovariant of Salmonella Typhimurium is frequently isolated from a large number of different foods and animals.
\end{abstract} piglets, 24 samples of non-processed meat, 28 meat preparations and 4 meat products. All samples were processed with an initial screening using the real-time PCR MicroSEQ® Salmonella spp detection Kit (Applied biosystems, life technologies) and with the TaqMan ${ }^{\circledR}$ Real-time PCR to confirm the kit results. Samples that tested positive for Salmonella spp were confirmed with cultural method using the standard ISO 6579. Positive samples were submitted to phenotypic identification. One colony from each positive sample was serotyped with multiplex PCR method. Salmonella spp was isolated in 7 on 166 samples $(4.22 \%)$. Among the positive samples, two came from finishing pigs, two belonged to the category meat preparations, two to meat products, one was an environmental sample. Multiplex PCR confirmed that the collected strains belonged to the species Salmonella Typhimurium (1), Salmonella derby (3) and monophasic serovariant of Salmonella Typhimurium (3).

\section{Introduction}

Salmonella spp is the second zoonotic agent responsible in Europe of about 95.000 confirmed cases of foodborne salmonellosis each year (EFSA and ECDC, 2017). Data related to pig meat in Europe shows a prevalence of $2.38 \%$ of Salmonella spp in fresh meat and $1.93 \%$ in ready to eat food minced meat, meat preparations and meat products (EFSA and ECDC, 2017). S. Enteritidis, $S$. Typhimurium and monophasic serovariant of Salmonella Typhimurium are the main serovariants involved in cases of human salmonellosis (EFSA and ECDC 2017).

The monophasic serovariant of Salmonella Typhimurium 4,5,12:i:- appears to be genetically related to Salmonella Typhimurium (which has the antigenic formula 4,5,12:i:1,2) but lacks in expression of the second phase flagellar antigen, which is 1,2 in Salmonella Typhimurium (Soyer et

Regarding the transmission methods of the microorganism, it has been demonstrated that the contaminations of pork products by Salmonella spp depend on two main factors: the origin of the animals and the application of good hygienic and manufacturing practices during slaughtering (Fois et al., 2017). EFSA reported a Salmonella prevalence of $6.7 \%$ at herd level and of $3.5 \%$ at animal level.

Salmonella prevalence at the farm level depend on various factor, as the origin and type of the feed, the management procedures, different types of herds like farrow to finish herds or fattening herds (Bonardi, 2017).

Pigs are healthy carriers of Salmonella spp, they can excrete the microorganism with feces or host it in tissues, particularly in the large intestine and ileum, in the lymph nodes or in the tonsils (García-Feliz et al., 2009). Some studies show that healthy carriers may shed Salmonella if subjected to stressful factors, such as the transfer to the slaughterhouse (Hurd et al., procedures and good manufacturing practices are not applied during slaughtering, 2002; Berardi, 2017). If animal welfare
Correspondence: Carlo Pala, Department of Food Hygiene, Institute for Experimental Veterinary Medicine of Sardinia, Sassari, Italy.

Tel.: +39.349 2695226

E-mail: carlopala@hotmail.it

Key words: Salmonella; monophasic serovariant of Salmonella Typhimurium; real-time PCR, pork meat.

Contributions: the authors contributed equally.

Conflict of interest: the authors declare no potential conflict of interest.

Funding: none

Received for publication: 20 September 2018. Revision received: 13 March 2019.

Accepted for publication: 12 April 2019.

This work is licensed under a Creative Commons Attribution-NonCommercial 4.0 International License (CC BY-NC 4.0).

CC Copyright C. Pala et al., 2019

Licensee PAGEPress, Italy

Italian Journal of Food Safety 2019; 8:7843

doi:10.4081/ijfs.2019.7843

Salmonella is disseminated over the carcasses or on the surfaces and equipment of the processing environments.

In Sardinia the pork industry is an important resource for the agricultural economy. There are approximately 16.000 small farms and there is an annual consumption of 50.000 quintals of pork meat, of which $35 \%$ is represented by pork products (Fois et al., 2017). However, local production accounts for less than $50 \%$ of the regional needs, making it necessary to import pigs from other European countries. Often in Sardinia were slaughtered pigs imported from different European countries.

A survey, including 19,071 pigs from 24 European countries, (EFSA, 2008) found an overall bacteriological prevalence in the mesenteric lymph nodes and feces of slaughtered pigs. This prevalence varied widely among participating countries (Davies, 2011). At mesenteric lymph nodes level, the prevalence of Salmonella ranges from $7,4 \%$ to $26 \%$ while the prevalence reported in faecal content is about $20-30 \%$ (Bonardi, 2017).

Contaminated carcasses are the main vehicle of Salmonella spp in the pork meat processing industry, as well as in distribution centers, meat cutting laboratories and sausage factories. Different levels of prevalence have been detected in pig carcasses in EU countries, ranging from 


\section{$0,35 \%$ to $17,41 \%$ (EFSA; ECDC).}

Once inside the environment, if good hygiene practices are not applied, Salmonella can persist within niches of the processing environment, protected by a structured biofilm ecosystem. Starting from these niches the microorganisms find their way to contaminate exposed food through direct contact, aerosol, dripping or water splashes and by means of operators (Simoes et al., 2009). Data provided by EFSA, reported an overall Salmonella prevalence of $0,5 \%$ in fresh pork and $0,7 \%$ in ready-toeat minced meat, meat preparations and meat products (Bonardi, 2017).

The aim of this study is to investigate the situation of Sardinian pig meat production in relationship with the contamination by Salmonella spp and to determine the prevalence of monophasic serovariant of Salmonella Typhimurium.

\section{Materials and Methods}

Between July 2017 and April 2018, an epidemiological survey was carried out over a total of sixteen structures between pork meat processing plants and slaughterhouses in Sardinia. In detail, environmental and products samples were collected in three EC slaughterhouses, four small slaughterhouses annexed to farmhouses, one meat distribution center, four meat cutting laboratories and four sausage factories. A single sampling day was conducted at each plant.

\section{Samples collection}

All samples were collected in 15 different food plants located in Sardinia. Meat industries and laboratories included in this study were: EC slaughterhouses (3); slaughterhouses annexed to a farmhouse (4); meat distribution center (1); meat cutting laboratories (4); sausage factories (4). The different number of samples collected from each food plant was proportional to its production capacity. A total of 166 samples were collected and analyzed: 46 environmental samples, 48 finishing pigs, 16 piglets, 24 samples of non processed meat (fresh meat before processing, fresh bacon), 28 meat preparations (minced meat, fresh sausage) and 4 meat products (fermented sausage). By way of illustration, the environmental samples included 20 surfaces not in contact with meat and 26 surfaces in contact with meat. Surfaces not in contact with meat, like walls, floors and floor drains were sampled in each visited plant (slaughterhouses, meat distribution center, meat cutting laboratories and sausage factories). Surfaces in contact with meat like mincing machine, mixing machine, sausage stuffers and trolleys were sampled at sausage factories; while cutting tables, saw machine and knives were sampled from each structure. The pig scalding dehairing machines was sampled at slaughterhouse. Environmental samples were collected using a commercial sponge sampling kit (3M, St. Paul, Minnesota, USA). Each kit contained a sterile sponge moistened with $10 \mathrm{~mL}$ of buffer peptone water (BPW), sterile gloves and sterile bag to transport the sponge. Sponges were scrubbed on the selected site, bounded with a sterile plastic delimiter, in order to cover an area of about $0.3 \mathrm{~m}^{2}$ (Carpentier \& Barre, 2012). Sponges were also used to sample the surfaces of finishing pigs and piglets carcasses, scrubbing the sponge on an area of $0.4 \mathrm{~m}^{2}$. From each carcass four point were swabbed: ham, back, belly and jowl. After collection, each sponge was placed into its sterile bag. Samples of about 100 grams were collected from non-processed meat, meat preparations and meat products and placed in a sterile bag. All samples were transported in coolers with ice packs $\left(3 \pm 1^{\circ} \mathrm{C}\right)$, received and processed at the Food Hygiene Department of Institute for Experimental Veterinary Medicine of Sardinia within 24 hours after collection.

\section{Screening with real-time PCR}

Detection of Salmonella in both environmental samples and product samples was performed using real-time PCR followed by microbiological confirmation (Bonardi et al., 2017). A pre-enrichment broth was prepared suspending the sponge in $90 \mathrm{~mL}$ of Buffered Peptone Water BPW (Oxoid, Basingstoke, UK), $25 \mathrm{~g}$ of nonprocessed meat and meat products in 225 $\mathrm{mL}$ of BPW and $10 \mathrm{~g}$ of meat preparations in $90 \mathrm{~mL}$ of BPW. All samples were placed into Paddle Blender Bagfilter ${ }^{\circledR}$ and homogenate in a stomacher blander. After $24 \pm 2 \mathrm{~h}$ at $37 \pm 1^{\circ} \mathrm{C}$ DNA was extracted from $750 \mu \mathrm{L}$ of the pre-enrichment culture using the PrepSEQ ${ }^{\mathrm{TM}}$ Rapid Spin Sample Preparation Kit Salmonella spp (Applied biosystems, life technologies). $30 \mu \mathrm{L}$ of the bead-free supernatant from the DNA preparation step was then transferred into the tubes of MicroSEQ ${ }^{\circledR}$ Salmonella spp Detection Kit containing lyophilized PCR reagents. Real-time PCR reactions were run on the Applied Biosystems 7500 Fast RealTime PCR System with the RapidFinder ${ }^{\mathrm{TM}}$ Express Software. The thermal profile used was: $95^{\circ} \mathrm{C}$ for 2 minutes, followed by 40 cycles at $95^{\circ} \mathrm{C}$ for 3 seconds and $60^{\circ} \mathrm{C}$ for 30 seconds. All samples were also processed with the TaqMan ${ }^{\circledR}$ Real-time PCR to confirm the kit results (Cremonesi et al., 2014). Using the DNA obtained with PrepSEQ ${ }^{\mathrm{TM}}$ Preparation Kit, the PCR reactions were performed in a final volume of $20 \mathrm{~mL}$ containing $2 \mathrm{~mL}$ of template genomic DNA, $10 \mathrm{~mL}$ of TaqMan Universal PCR Master Mix, $20 \mathrm{mM}$ for each primer, $5 \mathrm{mM}$ for probe, the TaqMan Exogenous Internal Positive Control (IPC) Reagents VIClabeled $(2 \mathrm{~mL}$ of the Exo IPC Mix) (primers/probe) and $0.5 \mathrm{~mL}$ of the Exo IPC DNA (target DNA) and $4 \mathrm{~mL}$ of molecular grade water. A DNA from target and nontarget reference strains correlating the designed assays was used. The reactions were carried out in 96-well plates sealed with heat bonding film. Amplification was achieved using an Applied Biosystems 7500 Fast Real-time PCR System (Life Technologies Inc, Italy). Each sample was tested in duplicate and the thermal profile used was: $50^{\circ} \mathrm{C}$ for 2 minutes, $95^{\circ} \mathrm{C}$ for 10 minutes, followed by 40 cycles at $95^{\circ} \mathrm{C}$ for 15 seconds and $60^{\circ} \mathrm{C}$ for 60 seconds. The samples with a cycle threshold (CT) lower than 40 were considered positive. The samples above this CT were considered negative for Salmonella spp.

\section{Microbiological analysis}

All real-time PCR positive samples were processed using conventional culturebased methods according to the International Organization for Standardization [ISO] (2017) protocol ISO $6579: 2017$. Starting from the same prearrichment PBW $\left(24 \pm 2 \mathrm{~h}\right.$ at $\left.37 \pm 1^{\circ} \mathrm{C}\right)$ used for biomolecular screening, from stomacher bag $100 \mu \mathrm{L}$ and $1 \mathrm{~mL}$ of samples were taken and mixed with $10 \mathrm{~mL}$ of Rappaport Vassialidis soya RVS broth (Oxoid) and Muller Kauffmann tetrathionate-novobiocin MKTTn broth (Microbiol \& C. s.n.c., Italy), respectively. Cultures were incubated overnight at $37 \pm 2^{\circ} \mathrm{C}$ for MKTTn broth and at $42 \pm 2^{\circ} \mathrm{C}$ for RSV broth. After the selective enrichment step, a loopful of each sample was streaked on selective and differential medium Xylose Lysine Desoxyscholate XLD (Microbiol) and ChromID ${ }^{\mathrm{TM}}$ Salmonella Agar SM2 (Biomerieux SA, France). Presumptive Salmonella colonies isolated on plating media were inoculated in Triple Sugar Iron semi-solid agar TSI (Oxoid) and incubated for $24 \pm 2 \mathrm{~h}$ at $37 \pm 1^{\circ} \mathrm{C}$. Cultures giving typical reactions for Salmonella were submitted for biochemical identification test Biochemical tests on suspected colonies were carried out using a miniaturized kit for rapid biochemical characterization of Salmonella Vitek 2 compact (Biomerieux).

\section{Typing of isolates}

Serotyping of isolates was performed following the White-Kauffmann-Le Minor 
scheme by slide agglutination with specific sera for $\mathrm{O}$ and $\mathrm{H}$ antigen. The phenotypically discrimination of monophasic variant from Salmonella Typhimurium was done by repeating phase inversion at least three times without getting expression of the phase-2 flagellar antigens. Subsequently the genotypical discrimination was carried out by multiplex PCR protocol previously described by Alvarez et al. (2004), by Tennant et al. (2010) and then partly modified by Barco et al. (2011). This method allows a simultaneous amplification of a fragment between the genes $f l j \mathrm{~B}$ and $f l j \mathrm{~A}$ and the phase-2 flagellar gene $(f l j \mathrm{~B})$. As described by Barco et al. (2011), template DNA was obtained by boiling of pure bacterial culture for $10 \mathrm{~min}$ utes. The PCR assay was performed in a total volume of $30 \mu \mathrm{L}$ containing $2.5 \mathrm{mM}$ $\mathrm{MgCl}_{2}, 0.6 \mathrm{mM}$ of dNTPs, 1X Buffer-Taq, 1U of AmpliTaq GoldTM DNA Polymerase (Applied Biosystems, Roche), $0.1 \mathrm{mM}$ of primers specific for fliB-fliA intergenic region, $1 \mathrm{mM}$ of primers specific for $f l j \mathrm{~B}$ gene, and $5 \mu \mathrm{L}$ of template DNA. The amplification profile was denaturation $\left(95^{\circ} \mathrm{C}\right.$ for 2 minutes), amplification (30 cycles: $95^{\circ} \mathrm{C}$ for 30 seconds, $64^{\circ} \mathrm{C}$ for 30 seconds, $72^{\circ} \mathrm{C}$ for 90 seconds), and final extension $\left(72^{\circ} \mathrm{C}\right.$ for 10 minutes)

\section{Results}

\section{Detection of Salmonella spp}

The CT values of both real-time PCR methods used in the study were lower than 40 in 13 out of 166 samples $(7.83 \%)$. Of the 13 positive samples, 2 were surfaces in contact with meat, 3 were carcasses of finishing pigs, 5 belonged to the category of non-processed meat, 2 were meat preparations and 1 was a fermented pork sausage. The prevalence calculated from the real-time PCR results is showed in Table 1.

Salmonella spp was isolated from 7 out 13 (53.85\%) of the PCR-positive samples, therefore the prevalence of Salmonella spp in all tested samples was 4.22\% (7/166).

Salmonella spp was isolated from 1 out of 3 EC slaughterhouses (33.3\%) and 3 out of 4 meat cutting laboratories $(75 \%)$.

The prevalence of Salmonella spp in the environmental samples was $2.17 \%(1 / 46)$. In particular the prevalence in samples of surfaces in contact with meat was $3.85 \%$
$(1 / 26)$. The microorganism was isolated from pig scalding dehairing machine in 1 out of 3 EC slaughterhouses visited. Salmonella spp was not isolated in the environmental samples not in contact with meat (walls, floors, floor drains). Results are showed in Table 2.

In regards to the carcass samples, a prevalence of $3.13 \%(2 / 64)$ was found. Positive samples belonged to the category of finishing pigs with a prevalence of $4.16 \%$ $(2 / 48)$ from 1 EC slaughterhouse out of 16 plants visited. Salmonella spp was not isolated in any piglet sample. Results are showed in Table 3.

Salmonella spp was isolated in 4 out of 56 food products, showing a prevalence of $7,14 \%$. Positive samples belonged to the categories "non-processed meat" (2 samples of pork bacon) and "meat preparations" (2 samples of fresh sausage). Results are showed in Table 4.

The serotyping of strains isolated in this study showed that the 7 Salmonella spp belonged to Salmonella Typhimurium (1/7), Salmonella derby (3/7) and monophasic serovariant of Salmonella Typhimurium $(3 / 7)$, with a prevalence of respectively $14.3 \%, 42.9 \%$ and $14.3 \%$.

Table 1. Prevalence of Salmonella spp with real-time PCR screening method.

\begin{tabular}{|c|c|c|c|c|c|}
\hline Samples & $\begin{array}{l}\text { EC } \\
\text { ghterhouses (3) }\end{array}$ & $\begin{array}{c}\text { Small } \\
\text { slaughterhouses (4) }\end{array}$ & $\begin{array}{c}\text { Plants } \\
\text { Meat cutting } \\
\text { laboratory (4) }\end{array}$ & $\begin{array}{l}\text { Sausage } \\
\text { factory (4) }\end{array}$ & $\begin{array}{l}\text { Meat distribution } \\
\text { center (1) }\end{array}$ \\
\hline $\begin{array}{l}\text { Environmental } \\
\text { SCM } \\
\text { SNCM } \\
\text { Total }\end{array}$ & $\begin{array}{c}16.7 \%(1 / 6) \\
\text { ne } \\
6\end{array}$ & $\begin{array}{c}\text { ne } \\
-(0 / 7) \\
7\end{array}$ & $\begin{array}{c}-(0 / 4) \\
-(0 / 1) \\
5\end{array}$ & $\begin{array}{c}6.25 \%(1 / 16) \\
-(0 / 10) \\
26\end{array}$ & $\begin{array}{c}\text { ne } \\
-(0 / 2) \\
2\end{array}$ \\
\hline $\begin{array}{l}\text { Carcasses } \\
\text { Finishing Pigs } \\
\text { Piglets } \\
\text { Total }\end{array}$ & $\begin{array}{c}9.1 \%(2 / 22) \\
- \\
22\end{array}$ & $\begin{array}{c}-(0 / 6) \\
-(0 / 12) \\
18\end{array}$ & $\begin{array}{c}16.7 \%(1 / 6) \\
-(0 / 3) \\
9\end{array}$ & $\begin{array}{c}-(0 / 4) \\
- \\
4\end{array}$ & $\begin{array}{l}-(0 / 10) \\
-(0 / 1) \\
11\end{array}$ \\
\hline $\begin{array}{l}\text { Product } \\
\text { Non-Processed Meat } \\
\text { Meat Preparations } \\
\text { Fermented pork sausage } \\
\text { Total }\end{array}$ & $\begin{array}{l}\text { ne } \\
\text { ne } \\
\text { ne }\end{array}$ & $\begin{array}{l}\text { ne } \\
\text { ne } \\
\text { ne }\end{array}$ & $\begin{array}{c}33.33 \%(4 / 12) \\
7.7 \%(2 / 26) \\
\text { ne } \\
38\end{array}$ & $\begin{array}{c}8.33 \%(1 / 12) \\
-(0 / 2) \\
25 \%(1 / 4) \\
18\end{array}$ & $\begin{array}{l}\text { ne } \\
\text { ne } \\
\text { ne }\end{array}$ \\
\hline
\end{tabular}

SCM, surfaces in contact with meat; SNCM, surfaces not in contact with meat. The number of positive samples out of the total is reported in brackets; -, not detected; ne, not evaluated.

Table 2. Prevalence of Salmonella spp in environmental samples in relationship with plants and sample categories.

\begin{tabular}{|c|c|c|c|c|c|}
\hline Samples & $\begin{array}{c}\text { EC } \\
\text { slaughterhouses } \\
\text { (3) }\end{array}$ & $\begin{array}{c}\text { Small } \\
\text { slaughterhouses } \\
\text { (4) }\end{array}$ & $\begin{array}{l}\text { Plants } \\
\text { Meat cutting } \\
\text { laboratory } \\
\text { (4) }\end{array}$ & $\begin{array}{l}\text { Sausage } \\
\text { factory } \\
\text { (4) }\end{array}$ & $\begin{array}{l}\text { Meat distribution } \\
\text { center } \\
\text { (1) }\end{array}$ \\
\hline SCM & $16.7 \%(1 / 6)$ & ne & $-(0 / 4)$ & $-(0 / 16)$ & ne \\
\hline SNCM & ne & $-(0 / 7)$ & $-(0 / 1)$ & $-(0 / 10)$ & $-(0 / 2)$ \\
\hline Total & 6 & 7 & 5 & 26 & 2 \\
\hline
\end{tabular}

SCM, surfaces in contact with meat; SNCM, surfaces not in contact with meat. The number of positive samples out of the total is reported in brackets; -, not detected; ne, not evaluated. 
Table 3. Prevalence of Salmonella spp in carcasses of finishing pigs and piglets in relationship with plants.

\begin{tabular}{|c|c|c|c|c|c|}
\hline Samples & $\begin{array}{c}\text { EC } \\
\text { slaughterhouses } \\
\text { (3) }\end{array}$ & $\begin{array}{c}\text { Small } \\
\text { slaughterhouses } \\
\text { (4) }\end{array}$ & $\begin{array}{c}\text { Plants } \\
\text { Meat cutting } \\
\text { laboratory } \\
\text { (4) }\end{array}$ & $\begin{array}{l}\text { Sausage } \\
\text { factory } \\
\text { (4) }\end{array}$ & $\begin{array}{l}\text { Meat distribution } \\
\text { center } \\
\text { (1) }\end{array}$ \\
\hline Finishing Pigs & $9.1 \%(2 / 22)$ & $-(0 / 6)$ & $-(0 / 6)$ & $-(0 / 4)$ & $-(0 / 10)$ \\
\hline Piglets & ne & $-(0 / 12)$ & $-(0 / 3)$ & ne & $-(0 / 1)$ \\
\hline Total & 2218 & 18 & 9 & 4 & 11 \\
\hline
\end{tabular}

The number of positive samples out of the total is reported in brackets; -, not detected; ne, not evaluated.

The multiplex PCR used to distinguish Salmonella Typhimurium from the monophasic serovariant of Salmonella Typhimurium confirmed that among the 4 strains of Salmonella Typhimurium, 3 lacked in expression of the second phase flagellar antigen.

\section{Discussion}

Data obtained by the initial screening using the real-time PCR method, showed a higher prevalence of Salmonella spp if compared with the results of microbiological analysis. One possible explanation could be the higher sensitivity of real-time PCR. This aspect has been demonstrated by several studies. In 2014 Rodriguez-Lazaro et al. observed that a real-time PCR protocol was able to detect down to 2-4 Salmonella CFU in $25 \mathrm{~g}$ of different samples, including raw pork. Other authors demonstrated that limit of detection of the ISO 6579:2002 is down to $10 \mathrm{CFU}$ per $25 \mathrm{~g}$, therefore the real-time PCR can represent an excellent alternative (Delibato et al., 2014). Furthermore, another possible explanation could be the ability of real-time PCR to amplify DNA also from dead microorganisms (Barbau-Piednoir et al., 2014), as probably happened in the fermented sausage sample and in the environmental sample.

This study showed a large variability in Salmonella prevalence among different plants. The obtained results confirmed what previously demonstrated by a study conducted by Piras et al., in 2014 on Sardinian abattoirs, affirming that contaminations depend on the slaughterhouse procedures (hygienic parameters and qualification of personnel), on the sampling day and on the origin and the number of infected pigs delivered during the same day. The positive carcasses to Salmonella, in one of three visited slaughterhouses, came from a European country (Spain), confirming that

Table 4. Prevalence of Salmonella spp in products in relationship with plants.

\begin{tabular}{lcc} 
Samples & Meat cutting laboratory (4) & \\
Non-Processed Meat & $16.67 \%(2 / 12)$ & Sausage factory (4) \\
Meat Preparations & $7.7 \%(2 / 26)$ & $-(0 / 12)$ \\
Fermented pork sausage & ne & $-(0 / 2)$ \\
Total & 38 & $-(0 / 4)$ \\
\hline
\end{tabular}

The number of positive samples out of the total is reported in brackets; -, not detected; ne, not evaluated.

subclinical infected pigs may start excreting Salmonella when they are exposed to stress for example during transfer to the slaughterhouse (Rostagno, 2009). In fact, in the present study Salmonella spp was never isolated in small abattoirs annexed to farmhouses, where only pigs born in the farm are slaughtered. The isolation of Salmonella from equipment, as the scalding dehairing machine, confirms the ability of the microorganism to adhere to steel surfaces and to produce biofilm, as demonstrated by Piras et al. in 2015. This aspect can increase the risk of cross-contamination for carcasses during the dehairing phases and the subsequent contamination of offal and meat. The non confirmation of positivity at the microbiological analysis in the environmental samples not in contact with meat, that were positives at real-time PCR, shows the effectiveness of good hygiene practices during pre and post operative cleaning phases. Overall, data on the prevalence of Salmonella spp concerning environments, products and Salmonella typing obtained in this work confirm the ones reported in literature (D'ostuni et al., 2016; Terentjeva et al., 2017). As demonstrated by several research, our study demonstrated that the most common Salmonella serovariant isolated from pig in the EU are Salmonella Typhimurium, Salmonella Derby and monophasic serovariant of Salmonella Typhimurium (Bonardi, 2017; Barilli et al., 2018; EFSA and ECDC, 2016).

\section{Conclusions}

The swine meat supply chain represents a potential alternative to the local agriculture as well as a strategic resource for the growth of the Sardinian economy, especially following the positive achievements obtained over the last years on animal health and breeding. Therefore, it becomes necessary to collect epidemiological data related to one of the most important anthropozoonotic agents carried by pigs in the industrial food chain.

Although in low prevalence, Salmonella appears to be present in slaughterhouses and products.

Considering the risk associated to Salmonella spp contamination in pig meat, the followings should be adopted as guideline: periodical monitoring of the meat supply chain (over all the steps of the process); enforcement of good hygiene practices and, whereas possible, restrict raw material selection to qualified farms.

The high sensitivity of real-time PCR, makes this method a complimentary alternative to the conventional microbiological techniques, especially for the initial sample screening that, once confirmed, are then processed according to the ISO. In light of the above, the real-time PRC allows to save time and improve response time efficiency mainly for the laboratories that perform a large number of checks. 
cation conditions. Food Microbiol 43:35-40.

\section{References}

Agasan A, Kornblum J, Williams G, Pratt CC, Fleckenstein P, Wong M, Ramon A, 2002. Profile of Salmonella enterica subsp. enterica (Subspecies I) serotype 4, 5, 12: i:- strains causing food-borne infections in New York City. J Clin Microbiol 40:1924-9.

Alvarez J, Sota M, Vivanco AB, Perales I, Cisterna R, Rementeria A, Garaizar J, 2004. Development of a multiplex PCR technique for detection and epidemiological typing of Salmonella in human clinical samples. J Clin Microbiol 42:1734-38.

Barbau-Piednoir E, Mahillon J, Pillyser J, Coucke W, Roosens NH, Botteldoorn N, 2014. Evaluation of viability-qPCR detection system on viable and dead Salmonella serovar Enteritidis. J Microbiol Methods 103:131-7.

Barco L, Lettini AA, Ramon E, Longo A, Saccardin C, Pozza MCD, Ricci A, 2011. A rapid and sensitive method to identify and differentiate Salmonella enterica serotype Typhimurium and Salmonella enterica serotype 4,[5], 12: i:-by combining traditional serotyping and multiplex polymerase chain reaction. Foodborne Pathog Dis 8:741-3.

Barilli E, Bacci C, StellaVilla Z, Merialdi G, D'Incau M, Brindani F, Vismarra A, 2018. Antimicrobial resistance, biofilm synthesis and virulence genes in Salmonella isolated from pigs bred on intensive farms. Ital J Food Saf 7:7223.

Bonardi S, 2017. Salmonella in the pork production chain and its impact on human health in the European Union. Epidemiol Infect 145:1513-26.

Bonardi S, Bruini I, Bolzoni L, Cozzolino P. Pierantoni M, Brindani F, Bellotti P, Renzi M, Pongolini S, 2017. Assessment of Salmonella survival in dry-cured Italian salami. Int J Food Microbiol 262:99-106.

Carpentier B, Barre L, 2012. Guidelines on sampling the food processing area and equipment for the detection of Listeria monocytogenes. French Agency Food Environ Occup Health Saf 1-15.

Cremonesi P, Pisani LF, Lecchi C, Ceciliani F, Martino P, Bonastre AS, Karus A, Balzaretti C, Castiglioni B, 2014. Development of 23 individual TaqMan ${ }^{\circledR}$ real-time PCR assays for identifying common foodborne pathogens using a single set of amplifi-
Davies PR, 2011. Intensive swine production and pork safety. Foodborne Pathog Dis 8:189-201.

Delibato E, Rodriguez-Lazaro D, Gianfranceschi M, De Cesare A, Comin D, Gattuso A, ... Saiz-Abajo MJ, 2014. European validation of real-time PCR method for detection of Salmonella spp. in pork meat. Int $\mathrm{J}$ Food Microbiol 184:134-8.

D’Ostuni V, Tristezza M, De Giorgi MG, Rampino P, Grieco F, Perrotta C, 2016. Occurrence of Listeria monocytogenes and Salmonella spp. in meat processed products from industrial plants in Southern Italy. Food Control 62:104-9.

European Centre for Disease Prevention and Control, European Food Safety Authority, European Medicines Agency, 2017. ECDC/EFSA/EMA second joint report on the integrated analysis of the consumption of antimicrobial agents and occurrence of antimicrobial resistance in bacteria from humans and foodproducing animals. EFSA Journal 15:4872.

European Food Safety Authority, European Centre for Disease Prevention and Control, 2016. The European Union summary report on trends of zoonoses, zoonotic agents and food-borne outbreaks in 2015. EFSA Journal 14:4634.

Fois F, Piras F, Torpdahl M, Mazza R, Consolati SG, Spanu C, Scarano C, De Santis EP, 2017. Occurrence, Characterization, and Antimicrobial Susceptibility of Salmonella enterica in Slaughtered Pigs in Sardinia. J Food Sci 82:969-76.

García-Feliz C, Carvajal A, Collazos JÁ, Rubio P, 2009. Herd-level risk factors for faecal shedding of Salmonella enterica in Spanish fattening pigs. Prev Vet Med 91;130-6.

Hurd HS, McKean JD, Griffith RW, Wesley IV, Rostagno MH, 2002. Salmonella enterica infections in market swine with and without transport and holding. Appl Environ Microbiol 68:2376-81.

Ido N, Lee KI, Iwabuchi K, Izumiya H, Uchida I, Kusumoto M, Iwata T, Ohnishi M, Akiba M, 2014. Characteristics of Salmonella enterica serovar 4,[5], 12: i:-as a monophasic variant of serovar Typhimurium. PLoS One 9:104380.

Mossong J, Marques P, Ragimbeau C,
Huberty-Krau P, Losch S, Meyer G, Moris G, Strottner C, Rabsch W, Schneider F, 2007. Outbreaks of monophasic Salmonella enterica serovar 4,[5], 12: i:-in Luxembourg, 2006. Eurosurveillance 12:11-2.

Piras F, Fois F, Mazza R, Putzolu M, Delogu ML, Lochi PG, Pani SP, Mazzette R, 2014. Salmonella prevalence and microbiological contamination of pig carcasses and slaughterhouse environment. Ital J Food Saf 3:4581

Piras F, Fois F, Consolati SG, Mazza R, Mazzette R, 2015. Influence of temperature, source, and serotype on biofilm formation of Salmonella enterica isolates from pig slaughterhouses. J Food Prot 78:1875-8.

Rodriguez-Lazaro D, Gonzalez-García P, Delibato E, De Medici D, GarcíaGimeno RM, Valero A, Hernandez M, 2014. Next day Salmonella spp. detection method based on real-time PCR for meat, dairy and vegetable food products. Int J Food Microbiol 184;113-20.

Rostagno MH, 2009. Can stress in farm animals increase food safety risk? Foodborne Pathog Dis 6:767-76.

Simoes M, Simoes LC, Vieira MJ, 2009. Species association increases biofilm resistance to chemical and mechanical treatments. Water Res 43;229-37.

Soyer Y, Switt AM, Davis MA, Maurer J, McDonough PL, Schoonmaker-Bopp DJ, Dumas NB, Root T, Warnick LD, Gröhn YT, Wiedmann M, 2009. Salmonella enterica serotype 4, 5, 12: i:-, an emerging Salmonella serotype that represents multiple distinct clones. $\mathrm{J}$ Clin Microbiol 47;3546-56.

Tennant SM, Diallo S, Levy H, Livio S, Sow SO, Tapia M, Fields PI, Mikoleit M, Tamboura B, Kotloff KL, Nataro JP, Galen JE, Levine MM, 2010. Identification by PCR of non-typhoidal Salmonella enterica serovars associated with invasive infections among febrile patients in Mali. PLoS Negl Trop Dis 4:621.

Terentjeva M, Avsejenko J, Streikiša M, Utināne A, Kovalienko K, Bērzinšs A, 2017. Prevalence and antimicrobial resistance of Salmonella in meat and meat products in Latvia. Ann Agric Environ Med 24:317-21. 